\title{
Kundalini and Healing in the West
}

\author{
Barbara Harris, RT, CMT \\ Baltimore, $M D$
}

\begin{abstract}
Kundalini rising, and associated profound physical, mental, emotional, and spiritual changes, are occurring with increasing frequency to uninitiated and unprepared Westerners, often as a result of near-death experiences. While these phenomena have been encompassed by Oriental medicine for centuries, they are unknown to traditional anatomically-based Western medicine. Without adequate knowledge or guidance, kundalini experiences may lead to ego inflation or "premature transcendence," paradoxically blocking spiritual evolution. A new paradigm in health care, emerging as a complement to traditional Western medical science, incorporates a variety of body-based and psychological therapies that validate the role of the True Self in health and wholeness and work with energetic and experiential phenomena such as kundalini.
\end{abstract}

Phenomena associated with kundalini rising, linked to near-death experiences (NDEs) in the Spring 1994 issue of the Journal (Jourdan, 1994; Kason, 1994; Kieffer, 1994; Wile, 1994), are occurring more and more to Westerners who have never heard of it, and, like near-death experiencers, have done nothing intentionally to arouse it. Felt as vast rushes of energy through the body, kundalini rising can create profound changes in the structure of people's physical, mental, emotional, and spiritual lives.

Barbara Harris, RT, CMT, is a certified massage therapist in private practice in Baltimore, MD. Reprint requests should be addressed to Ms. Harris at 31 Walker Avenue, Suite 100, Baltimore, MD 21208. 
For thousands of years Oriental medicine has included the kundalini model and used it in healing modalities such as acupuncture, Shiatsu, and Jin Shin Jyutsu. We in the Western world have observed acupuncture being used for anesthesia during surgery and for relief of pain. We know that it works, but we just don't know how it works. Today, many "new paradigm" therapists and health care practitioners in America and Europe are using modalities based on this energy model in their work and getting excellent results. Even though our American schools of medicine, nursing, and physical therapy have not yet understood or accepted this model, the energy does exist, and awakening it and/or working with it on its own subtle level does affect and help heal the physical body. Perhaps Western medicine has never included the awareness of this energy because originally most of what was known of the human body was based on autopsies, and there is obviously no energy in the body after death. But even today with medicine's advances, most physicians are not aware of kundalini or of its potential usefulness in their work.

In my first book, Full Circle (Harris and Bascom, 1990), I described kundalini as a natural phenomenon with intense psychological and physical effects, which can catapult the individual into a higher state of consciousness. I would add now that the kundalini system is based on the experiential reality that we are each extensive fields of consciousness intimately related to our biological bodies. As fields of consciousness we have an energy/spirit-body. All kinds of experience can manifest in our energy/spirit-body. These experiences can be highly emotional and are usually connected to activities in the autonomic nervous system and the hormonal, nervous, and muscular systems of the biological body. These experiences can be repressed in our memories but are also manifested as stress in our energy/spirit/biological bodies. Felt as "blocks in our energy," they can be released resulting in release of emotional and physical stress and recovery of forgotten memories. Thus, kundalini is fueled by emotion and helps us to release a lifetime of buried stress resulting in a healthier body, physically, emotionally, mentally, and spiritually.

Shiatsu, polarity, acupuncture, acupressure, Reichian body work, bioenergy integration, holotropic integration, tai chi, and other forms of therapeutic massage utilize the concept of underlying energy that can be released. Whether this energy is called chi, ki, prana, kun- 
dalini, bioenergy, Holy Spirit, vital force or simply energy, the assumptions about it are similar.

In discussing the energy model, there is a common limitation set up by the tendency to concretize the energy, to view the energy as physical stuff with physical properties. The concept of energy in the human body and any living form should be contemplated as a verb, not a noun. There is no such thing as energy in physical form. There is the activity that is described in energetic terms. In this sense, energy moves rather than exists statically, as in an electrical storage battery. So when we speak of life energy, we describe activity, not a measurable physical entity.

According to the Chinese explanation of the energy model, energy is seen to be like the wind, which is invisible, but which has visible effects, such as waves on top of a pond stirred by a breeze. The concept of energy is a useful way of describing the deeper hidden patterns, deeper processes that underlie the visible effects. In the final analysis, the results of the energy, the visible waves on the pond, can be seen in the lives that we lead, the love that we share, and the selfless service that we extend. "By their fruits you will know them" (Matthew 7:20).

I have heard hundreds of stories from people throughout the United States and Canada, and received letters from all over the world, of kundalini arousal. When I worked with Bruce Greyson at the University of Connecticut, experiencers with kundalini signs and symptoms would come to our Friends of IANDS support group, call us, or write voluminous letters. They were usually concerned, often scared, and always wanting to know more and help in the research. Occasionally they claimed to be authorities in this area that has often been clouded and hidden within the occult jargon of the Eastern esoteric schools since the beginning of recorded history. We have even been faced with contemporaries who claim that their kundalini awakening has transformed them into gurus.

One of the biggest problems at this early stage of understanding this transformational process is ego inflation. Many read the Eastern literature and may identify strongly with the gurus. But we are Westerners, and it is hard to translate these Eastern metaphors when our cultural roots are so different. Eventually, most of us pass through this stage, realizing that we have not been raised in the East. Many also develop psychic abilities and many believe that this is the "powerful" end result. They fixate on being psychic, resulting again in ego inflation. Our reward for working through ego 
inflation is humility, which is a solid foundation of an authentically spiritual, healthy, and whole human being. Humility is the willingness to continue learning our whole lives. Being humble is that state of being open to experiencing and learning about self, others, and God. In this openness we are free not only to avoid any of the pitfalls of ego inflation, but we are also free to connect with God again, here, in this reality. In this state of humility and "second innocence," we can more easily and consciously experience whatever comes up for us.

Some never experience ego inflation and others may get stuck in it. The secret is to work on ourselves psychologically as well as spiritually. Kundalini rising does not instantly heal us. To believe so is to attempt what Charles Whitfield $(1987,1991)$, I (1995), and others call a "spiritual bypass." We try to bypass our own shadow/darkness to get to the Light, ignore the lower to get to the higher levels of consciousness. Eventually, however, our shadow will pull us back until we work through our particular unfinished business. Other names for this are "high level denial" and "premature transcendence." This is seen in any number of situations, from being prematurely "born again" to having a spiritual awakening and focusing only on the Light, or focusing on psychic ability as a major part of our identity, to becoming attached to a guru or "way."

Kenneth Ring (1984) referred to deep near-death experiences as "core experiences." In the NDE, we were the core of who we really are, or our True Self. Ego inflation prevents us from being our core True Self. If we live from our ego or false self, we feel separated and alienated, empty and with no meaning. In its extreme, our negative ego or false self will even try to convince us that it is God! We can only experientially connect with God, each other, and our selves by developing our core True Self. Ego inflation is more of a cognitive or intellectual experience, a head trip. Being our True Self and connecting spiritually with God is a heart experience.

The mechanism of kundalini brings us home to our True Self. Cooperating with it, being patient with ourselves, and getting what we need (including therapy, body-based and psychological) not only brings us to our True Self, but also to our connection with others and especially to God as we feel God in our experiences. Kundalini shows us that we don't have to wait to die again. God and Home are here and now if we invite this divine energy to guide us and help us do our homework. 


\section{References}

Harris, B. (1995). Spiritual awakenings. Deerfield Beach, FL, Health Communications (1-800-851-9100).

Harris, B., and Bascom, L. C. (1990). Full circle: The near-death experience and beyond. New York, NY: Pocket Books.

Jourdan, J.-P. (1994). Near-death and transcendental experiences: Neurophysiological correlates of mystical traditions. Journal of Near-Death Studies, 12, 177-200.

Kason, Y. (1994). Near-death experiences and kundalini awakening: Exploring the link. Journal of Near-Death Studies, 12, 143-157.

Kieffer, G. (1994). Kundalini and near-death experiences. Journal of Near-Death Studies, $12,159-176$.

Ring, K. (1984). Heading toward omega: In search of the meaning of the near-death experience. New York, NY: Morrow.

Whitfield, C. (1987). Healing the child within. Deerfield Beach, FL: Health Communications.

Whitfield, C. (1991). Co-dependence: Healing the human condition. Deerfield Beach, FL: Health Communications.

Wile, L. C. (1994). Near-death experiences: A speculative neural model. Journal of Near-Death Studies, 12, 133-142. 